\title{
Social Contract as a Tool for Stimulating Entrepreneurial Initiative of Low-Income Citizens
}

\author{
Submitted 06/06/20, $1^{\text {st }}$ revision 14/07/20, $2^{\text {nd }}$ revision 18/08/20, accepted 15.09/20 \\ Tatyana Romanova ${ }^{1}$, Venelin Terziev ${ }^{2}$, Olga Andreeva ${ }^{3}$, Anna Sukhoveeva ${ }^{4}$, \\ Elena Kravchenko ${ }^{5}$ Anna Antsibor ${ }^{6}$
}

\section{Abstract:}

Purpose: The article highlights topical issues on the development of the social contract technology as a tool for stimulating entrepreneurial initiative of low-income citizens and the ways to address these issues.

Design/Methodology/Approach: Present-day strategic priorities of socio-economic development in a civilized State comprise, first and foremost, poverty reduction and promotion of small and medium-sized enterprises. The promising tool able to influence the achievement of the mentioned goals simultaneously is deemed to be such a technology of state social assistance as social contract with individual enterprise being one of its orientations. However, despite progressive opportunities, this social contract orientation has not become widespread in Russia yet, and the reasons for this state of affairs and prospects demand scientific justification.

Findings: The necessity for formation and development of the targeted state assistance on the basis of the social contract technology in Russia taking into account the experience of other countries has been justified. The analysis of implementation of the social contract technology in practice has led to defining factors hindering its active application.

Practical Implications: The algorithm of actions, implied by the social contract for aid recipients, and weak points of its implementation have been determined.

Originality/Value: The authors have formulated proposals on further improvement of the social contract technology in terms of stimulating entrepreneurial initiative of low-income citizens.

Keywords: Poverty, low-income citizens, targeted social assistance, social contract.

JEL codes: H53, H55, H75, I3.

Paper type: Research article.

\footnotetext{
${ }^{1}$ Rostov State University of Economics, Department of Finance, Rostov-on-Don, Russian Federation, kafedrafinance@mail.ru

${ }^{2}$ University of Rousse, Rousse, Bulgaria, ORCID: 0000-0003-1115-8877, terziev@ skmat.com. ${ }^{3}$ Rostov State University of Economics, Center for Strategic Research of Socio-Economic Development of the South of Russia, Rostov-on-Don, Russian Federation, ORCID: 0000-00025567-6396,olvandr@yandex.ru.

${ }^{4}$ Rostov State University of Economics, Department of Finance, Rostov-on-Don, Russian Federation, suhoveeva_anna@mail.ru

${ }^{5}$ Rostov State University of Economics, Department of Finance, Rostov-on-Don, Russian Federation, kew62@inbox.ru

${ }^{6}$ National Research Nuclear University "MEPhI" (Moscow Engineering Physics Institute), Volgodonsk, Russian Federation, anna-ancibor@yandex.ru
} 


\section{Introduction}

In the current conditions, priority tasks of state policy in the majority countries across the world, including Russia, are reduction in social inequality and poverty alleviation. These issues have become most urgent in the terms of actions to overcome consequences caused by the spread of the coronavirus infection COVID-19, as the resulting economic shock of which has triggered the development of unfavorable socio-economic tendencies leading to the growth of the population's demands for social support, among which are: intensive nation's impoverishment generating high differentiation, bringing about a considerable decline of the living standards and pushing an ever-growing number of people to lower borders of living and social minimum; rising unemployment and steady growth dynamics of all its forms; sociopsychological tension among the majority of working population connected with concerns to lose their jobs and etc.

In response to the identified tendencies the Russian Federation has introduced an unprecedented number of measures of social security, ensuring financial support for citizens in need, as well as families with children. However, the measures taken are mainly of urgency and are not targeted to form long-term basis to maintain adequate standards of living for recipients of social assistance. The current situation along with the limited state financial resources justifies extensive implementation of such social support mechanisms which are not only supportive (passive) but capable of activating economic potential of employable low-income citizens leading to subsequent selfreliance and active involvement in the labour market (Sukhoveeva et al., 2017). In our view, one of such promising instruments is the technology of social contract which is in the outmost conformity with the principle of targeting and favours citizens truly in need for support (Bychkov et al., 2015; Andreeva et al., 2016; Nazarov, 2017; Ovcharova and Gorina, 2017; Romanova et al., 2019a).

A social contract is an agreement between a low-income citizen (a low-income family) and a local social security authority. Under this agreement the social security authority is obliged to provide state social assistance, while the recipients of the assistance assume the obligations to fulfill the activities of the social adaptation programme, specified by the contract.

Implementation of the technology of state social assistance on the basis of social contract is targeted at leading low-income citizens to higher standards of living due to constant independent income sources in cash and in kind.

According to the experts (Prokofieva, 2010; Tatarintsev, 2016; Keller, 2018; Kalashnikov et al., 2019; Kravchenko, 2019), the social contract technology complies with the requirements of the market-oriented economy and aims to improve living standards of citizens, to moderate social disproportions and social differentiations, to overcome social dependency, as it offers an opportunity for financially vulnerable citizens to efficiently change their financial status with the help of provided "start-up 
capital" or professional potential.

The very idea to implement social contract into the Russian social security system is based on the experience of foreign countries in introduction of similar mechanisms. The social contract method initially emerged in the USA in the second half of the 20th century and was oriented to poor citizens and families. At present international experience proves the existence of a considerable number of programmes targeted at providing social benefits which depend on whether a recipient observes certain conditions. For example, such programmes are "Income of active solidarity" (France), "New direction" (Great Britain), "Family pocket" (Brazilia), "Progress" (Mexico) (Puzyreva, 2018), "Solidarity" (Chilly) (Johannsen et al., 2010). The new model of social assistance on the basis of social contract is in force in the Republic of Kazakhstan since 2018 (project Өрлеу).

As the conducted research revealed, in Russia the experiment of providing targeted social assistance on the basis of social contract was put into action in the early 2000s. Initially it was held in Syktyvkar of Komi Republic and Perm of Perm region (since 2005 - Perm Krai). Later on, based on the results of the experiment, the method received official recognition by means of adopting new laws on targeted social assistance in a number of regions of the country.

At the beginning of 201876 members of the Russian Federation had implemented the social contract technology into the regional social security system. Furthermore, main directions of actions stipulated by the social contract for recipients of assistance are:

- measures to overcome difficult circumstances;

- provision of social services to families while the social contract is in force;

- development of individual household plots (private farmers);

- improvement of professional status and more active seek for work (registration in the employment service, professional training/retraining);

- start-up or development of individual enterprise.

We deem progressive opportunities of the social contract technology for overcoming poverty in the Russian practice to be used insufficiently. First and foremost, it concerns such a direction of the social contract as assistance with start-up or development of individual enterprise. The study shows that only in 4 regions this component has received relatively wide adoption: in Sevastopol (33\% in the structure of all social contract directions); in Kaliningrad region (28\%); in Sakhalin region (27\%); in Sakha Republic (Yakutia) (25\%); but in 31 regions implementing the social contract technology there is no such direction at all. Meanwhile, this very direction of social contract allows addressing two coherent tasks: leading low-income citizens to selfreliance, and consequently poverty reduction in the country, on the one hand, and development of small and medium-sized enterprises, from the other. Entrepreneurship is indeed an important element of market economy without which no state can develop in harmony (Romanova et al., 2019b). In particular, development of small and mediumsized enterprises contributes to efficient competitive economy, which ensures nation's 
650

high living standards. Besides, entrepreneurship is an effective instrument to reduce unemployment as it provides vast opportunities for population self-employment which is a topical matter nowadays.

In addition, the social contract technology can become one of the key instruments for the development of such an enterprise branch as social entrepreneurship (Golovko et al., 2019), the importance of which is recognized by both the scientific community (Albekov, 2020) and governments, non-government and international organizations from different countries. Thus, for instance, in the European Union it is essential that compared to other sectors this one has demonstrated its economic and social potential to better address the economic crisis (Terziev et al., 2020). As well in this regard Russia is interested in the experience of the implementation of the project for establishing Centres for Employment and Social Assistance in Bulgaria in the period 2015-2017 as a model of the provision of integrated employment and social assistance services aiming at increasing the efficiency of coordination and work in Employment Agency and Social Assistance Agency and enhancing social inclusion (Terziev, 2020).

The purpose of the study is to define topical issues on the development of the social contract technology as a tool for stimulating entrepreneurial initiative of low-income citizens and the ways to address these issues.

\section{Methodology}

The development of theoretical bases of social protection for citizens is possible with due regard for new provisions defined in modern scientific studies and stipulating a modification of approaches to the State social policy -economic (State) theory of social investments. Russian scholars have not rethought its postulates yet with respect to social protection for citizens, while they imply the necessity and opportunity of implementing new methods and instruments into the social security system, which are aimed at establishing conditions, stimulating, first of all, the growth of self-reliance and only then - at providing other measures of social support (Albekov et al., 2018).

The study is distinguished by a cross-disciplinary approach to the problem and its consideration in the context of changing models and practices of social support for population at the federal and regional levels.

Statistical methods allowed us to describe the rate and dynamics of poverty in the country, development indices of individual enterprises, to define trends and scales of the development of the social contract technology with regard to the impact on entrepreneurship activity.

The study was conducted on the basis of the examination of scientific literature, data from official websites of the authorities and organizations providing social protection for the population, results of sociological surveys. 


\section{Results}

One of the major sources of the economic growth of Russia is the development of entrepreneurship, which contribution to the country's GDP by 2024 should reach $40 \%$ and the number of the engaged in this domain should rise to 25 million people. This strategic goal was set in the Message of the President of the Russian Federation to the Federal Assembly dated March 1 ${ }^{\text {st }}$, 2018. In this message the President pronounced one more goal of the country's strategic development - to halve the poverty level. The coronavirus COVID-19 pandemic has considerably hindered the achievement of these goals but has not abolished them.

To achieve the strategic priorities established in the country it is in particular necessary to ensure a steady growth of the economic activity. In 2019 the number of actually functioning individual enterprises made 2738576 people, what is up by 215001 people compared to 2016. The number of employed workers engaged in the domain of individual enterprise activity for the period under review grew by 379060 people. However, despite such a positive trend of the entrepreneurship initiative, it should be marked that the quoted numbers have not reached the maximum, reported in 2008.

At the end of 2019 in Russia there were 18,1 million of people with money incomes lower than subsistence wage or $12,3 \%$ of the total population of the country (table 1 ). At the same time it should be mention, that up to $31,5 \%$ of poor population comprise employable citizens with a high economic potential. These particular people can be the target group of the State assistance in the framework of the entrepreneurship social contract.

Table 1. Population in Russia with money incomes below the subsistence level (20102019)

\begin{tabular}{|c|c|c|c|c|c|}
\hline \multirow{2}{*}{ Year } & \multicolumn{2}{|c|}{$\begin{array}{c}\text { Population with money } \\
\text { incomes below subsistence } \\
\text { level }\end{array}$} & \multicolumn{2}{|c|}{ Money income deficit } & Subsistence wage, \\
& $\begin{array}{c}\text { RuB per month } \\
\text { people }\end{array}$ & $\begin{array}{c}\text { percentage of } \\
\text { overall population }\end{array}$ & $\begin{array}{c}\text { bln. } \\
\text { RUB }\end{array}$ & $\begin{array}{c}\text { percentage of overall } \\
\text { money income of } \\
\text { population }\end{array}$ & \\
\hline 2010 & 17,7 & 12,5 & 375,0 & 1,2 & 5688 \\
\hline 2011 & 17,9 & 12,7 & 424,1 & 1,2 & 6369 \\
\hline 2012 & 15,4 & 10,7 & 370,5 & 0,9 & 7306 \\
\hline 2013 & 15,5 & 10,8 & 417,1 & 0,9 & 8050 \\
\hline 2014 & 16,3 & 11,3 & 482,7 & 1,0 & 9701 \\
\hline 2015 & 19,6 & 13,4 & 701,7 & 1,3 & 9828 \\
\hline 2016 & 19,4 & 13,2 & 701,8 & 1,3 & 10088 \\
\hline 2017 & 18,9 & 12,9 & 702,5 & 1,3 & 10287 \\
\hline 2018 & 18,4 & 12,6 & 699,0 & 1,2 & 10890 \\
\hline 2019 & 18,1 & 12,3 & 721,6 & 1,2 & 7306 \\
\hline
\end{tabular}

Source: Compiled by the authors on the basis of GKS, 2020

In March of 2020 the Civic Chamber of the Russian Federation and the Russian State 
social university conducted a sociological survey on the attitude of the Russian population towards social contract as a form of interaction between the State and lowincome families. The results of the survey revealed that the majority of families do not consider social entrepreneurship to be a goal for the sake of which they are ready to draw a social contract: approximately one-fifth (19\%) do not want to be engaged in social entrepreneurship in particular, and approximately two-thirds (63\%) do not consider entrepreneurship at all. During the survey the respondents shared their opinion on the reasons hindering the development of the State assistance based on social contract. We should review the main reasons in more detail.

The key problem in the citizens' view is that sums allocated by the government are not sufficient to set up an enterprise. $29 \%$ of the respondents share this point of view. It should be noted that the amount of the allowance proposed under the social contract to set up your own business is defined by the regions of the Russian Federation autonomously and first of all depends on the costs forecasted in the business-plan of a prospect aid recipient, as well as on the financial capacity of a region. Since 2020 in a number of pilot regions the maximum allowance amount has been increased by 2,5 times and makes 250000 rubles. This initiative emerged due to the fact that in 2020 the Russian Federation launched a pilot federal project on testing the implementation of social contract in the social security system with planned obligatory distribution of this practice all over the country in future. 21 regions have taken part in this pilot project and received the subsidy from the federal budget.

Among those regions are Altay, Bashkortostan, Komi, Mari El, Mordovia, Tatarstan, Tyva, Kabardino-Balkarya, Udmurtiya, Chuvashia Republics; Altay, Perm and Primorsky territories; Vologda, Ivanovo, Kurgan, Lipetsk, Nizhny Novgorod, Novgorod, Saratov and Tomsk regions. Due to the support from the federal budget these regions have increased the amount of the allowance for citizens willing to draw a social contract to set up and do business. According to the authors' opinion, in future, subject to the distribution of the pilot project all over the country, this condition to a certain extent will serve as a great stimulus for low-income citizens to set up their own business. On the other hand, it is obvious that even the amount of 250000 rubles considerably limits the list of possible business directions, besides, if for rural areas this amount will be sufficient to set up an enterprise, for poor citizens living in big cities it is clearly not enough. As we see it, for this application of social contract it is necessary to elaborate multiplying coefficients which allow to increase the amount of the allowance provided for a start-up, as well depending on such factors as type of entrepreneurial activity, region and residence area of an addressee.

Another significant issue preventing low-income citizens from engaging in entrepreneurship is the lack of required knowledge and qualification. This point of view is shared by $24 \%$ of the respondents. In our opinion, in the initial phases of interaction between social security agencies and prospect participants of the social contract programme it is necessary to involve subject-matter experts who could provide advice and expert support both at the stage of preparing a business-plan and 
evaluating possible risks of its implementation and at the stage of elaborating an individual adaptation programme. In this regard it is interesting to consider the experience in Novgorod region, where since 2020 in the social security system they have social managers who not only monitor how families use social contract funds, but their prior task is to consult and assist citizens with all issues arising from the social contract. A supervisor's advice is in particular demand when citizens are inclined to set up or develop their own business.

It is worth mentioning that low-income citizens often lack necessary skills how to set up and manage an enterprise, how to maintain accounting and tax records and etc. It is reasonable to provide low-income citizens who conclude the social contract to engage in entrepreneurship with an opportunity to conclude a social contract for training at the same time. Currently low-income citizens do not have such an opportunity as in accordance with the approved laws and regulations of the members of the Russian Federation they can conclude just one social contract. The opportunity to conclude a contract for training (skills development) in addition to the social contract for engaging in entrepreneurship will provide a significant synergetic effect for transferring to self-reliance.

One more factor hindering diffusion of the technology of the social contract to set up an enterprise is the limited list of possible application areas. $22 \%$ of the respondents agree on this issue. Indeed, at present the funds of the social contract can be spent mainly on purchasing fixed assets required for business, including purchasing equipment, creating and equipping additional workplaces, on condition that a citizen will be registered as an individual entrepreneur or peasant farm enterprise. However, at the initial stage in the majority of cases there is a need for other associated costs, for example, providing working capital, rental and utility payments and etc. in this respect it is justified to broaden the list of expenses which can be covered the funds received in the framework of the social contract.

Here as well we should name one more problem connected with duration periods of a social contract and an individual adaptation programme, which are currently limited with 6 months or one year. The duration of the social contract exceeds one year only in 5 regions, namely in Amur region, Tver region, Republic of Buryatia, Republic of Bashkortostan, Khabarovsk region. Our proposal is to prolong the social contract period to 18 months for entrepreneurs engaged in agricultural or farming areas. Such a necessity is caused by the fact that for some types of enterprises, for example, livestock, a production cycle takes not less than a year and a half.

Speaking about reasons hindering diffusion of the social contract practice aiming at starting individual enterprises, we should highlight one more sociological survey conducted by NAFI Research Centre. According to this survey about $76 \%$ of interviewed low-income citizens are not aware of the social contract technology and of assistance options which they can receive in this regard. Moreover, in our opinion, it is essential that the overwhelming majority of these citizens refer to the youth 
654

category. After all, that is the potential of young people as most active group of the society for the economic growth which is hard to overestimate as youth entrepreneurship can be deemed as a promising sector of business activity due to a number of reasons, among which we can particularly mark addressing employment needs, readiness and ability to apply new solutions, including digital and technological, increased tendency to take risks, which is a significant feature for an entrepreneur and etc., (Andreeva and Sukhoveeva, 2020). Thus, it is essentially important to inform the greatest possible number of young people referred to the lowincome category on the social contract technology and successful practices of its implementation.

At present the key tool of the existing system of State support for entrepreneurial activity in the country is National project on "Small and medium-sized enterprises and support for individual entrepreneurial initiative", which comprises 5 Federal projects: "Improvement of conditions for maintaining entrepreneurial activity"; "Expanding access of SMSE subjects to financial resources, including concessionary financing"; "Acceleration of SMSE subjects"; "Establishment of support system for farmers and development of rural corporation"; "Popularization of entrepreneurship".

At the same time the conducted research has allowed to conclude that Sate support provided under the social contract for organizing and maintaining entrepreneurial activity is not integrated into the general system of measures of State support for subjects of small and medium-sized enterprises, which are being implemented in the framework of National project on "Small and medium-sized enterprises and support for individual entrepreneurial initiative". In our opinion, this situation considerably limits promotion of this technology among low-income citizens, including the aspect of receiving necessary consulting services at all stages of the life cycle of an enterprise, not only at the stage of organizing business and elaborating a businessplan. We believe that consolidation of social and other sectorial measures of the State support for low-income citizens will ensure the fullest engagement of unemployed employable citizens in entrepreneurial activities.

\section{Conclusions}

Thus, the research shows that social contract has the potential to become an efficient tool for stimulating entrepreneurial initiative of low-income citizens providing the opportunity to obtain self-reliance and improve their living standards on a long-term basis. Besides, at present this application of the social contract has not become widely adopted. In our opinion it is necessary to improve the implementation of this State assistance technology in the following areas:

- to provide an opportunity to conclude a social contract proactively, which allows the majority of required data and documents to be received from a citizen not in paper, but digitally - by means of interdepartmental cooperation;

- to introduce multiplying coefficients allowing to increase the amount of the 
allowance provided for a start-up, depending on such factors as type of entrepreneurial activity, region and residence area of an addressee;

- to elaborate an opportunity to conclude a social contract for maintaining entrepreneurial activity and for training at the same time;

- to expand the list of expenses to cover which one can use the funds received under the social contract;

- to prolong the duration of the social contract to 18 months for entrepreneurs planning to develop in agricultural and farming sector;

- to enhance informing and awareness-raising on advantages of the social contract and its terms, first and foremost, among young people;

- to integrate social contract with other sectorial measures of support in the domain of small and medium-sized businesses, agriculture, to involve more subject-matter experts and municipal representatives at the early stage of the social adaptation programme.

\section{References:}

Albekov, A.U. 2020. Social entrepreneurship and non-profit organizations: current state, problems and prospects of development in a changing world, 488, DOI: $10.18334 / 9785912923173$.

Albekov, A.U., Romanova, T.F., Andreeva, O.V., Sukhoveeva, A.A. 2018. Current state, problems and priority areas of social policy in contemporary Russia. European Research Studies Journal, 4(21), 3-10.

Andreeva, E.I., Bychkov, D.G., Grishina, E.E., Emtsov, R.G., Feoktistova, O.A. 2016. Efficiency of social support of the population. Version 3.0: Targeting, needs, versatility, available at: https://www.nifi.ru/ru/activity/research-projects.

Andreeva, O.V., Sukhoveeva, A.A. 2020. Youth entrepreneurship and efficient tools of its development. CITISE, 2, 385-393.

Bychkov, D.G., Feoktistova, O.A., Andreeva, E.I. 2015. Inventory of budgetary measures in the area of social security of the population: ways to targeting measures of social support. Finance and credit, 41(665), 22-34.

GKS. 2020. Federal State statistics service. Available at: http://www.gks.ru/wps/wcm/connect/rosstat_main/rosstat/ru/statistics/population/le vel/.

Golovko, M.V., Agapova, S.P., Antsibor, A.V., Sukhoveeva, A.A., Andreeva, O.V. 2019. Social entrepreneurship as a promising way to economic security. Dilemas contemporáneos: Educación, Política y Valores, S7(6), 33.

ILO. 2010. Extending social security to all: A guide through challenges and options. International Labour Office, Social Security Department. Geneva, ILO, 83-84.

Johannsen, J., Tejerina, L., Glassman, A. 2010. Conditional Cash Transfers in Latin America: Problems and Opportunities, Social assistance and conditional cash transfers proceedings of the regional workshop. Mandaluyong City, Asian Development Bank, 139-140.

Kalashnikov, S.V., Tatarintsev, V.E., Margolin, A.M., Khrapylina, L.P. 2019. Risks of implementation of social contracts in regions of Russia. Issues of State and municipal management, 4, 7-30.

Keller, P.A. 2018. Social contract as a form of state social assistance to low-income groups, Theories and problems of political studies, 2A(7), 122-129. 
656

Kravchenko, E.V. 2019. Social contract as a promising mechanism to improve the efficiency of social protection. Russian journal of Labour economics, 2(6), 827-840.

Nazarov, V. 2017. Building an efficient social support system in Russia: targeting, neediness, common eligibility criteria. Moscow, Research Financial Institute, World bank, available at: http:// https://www.nifi.ru/ru/activity/research-projects.

Ovcharova, L.N., Gorina, E.A. 2017. Promoting the income-tested social support in Russia: barriers and facilitators. Economic Issues, 3, 5-21.

Prokofieva, L.M. 2010. Social contract - a new form of targeted state social assistance in subjects of the Russian Federation. Analytical Bulletin, 8(394), 6-79.

Puzyreva, A.A. 2018. State social assistance to needy citizens based on the mechanism of reciprocal obligations (social contract): evaluation of effectiveness and prospects of development. Omsk University Bulletin, Series: Law, 1 (54), 139-145.

Romanova, T.F., Andreeva, O.V., Sukhoveeva, A.A., Kaptsova, V.S. 2019a. Targeting the Principle Implementation in the System of Social Support. International Journal of Economics and Business Administration, S2 (7), 52-62, DOI: 10.35808/ijeba/370

Romanova, T.F., Popova, G.V., Sukhoveeva, A.A. 2019b. Development of tools of State support for small and medium-sized enterprises in the framework of results-based management. Financial economics, 11, 494-498.

Sukhoveeva, A.A., Antsibor, A.V., Gerasimova, K.A. 2017. Targeted social assistance as a tool for poverty reduction. Competitiveness in the global world: economics, science, technologies, 11(58), 651-654.

Tatarintsev, V.E. 2016. Opportunities and constraints of the increase of the social contract stability in Russia. Economics: Yesterday, Today and Tomorrow, 12A(6), 57-58.

Terziev, V. 2019. Efficiency and assessment of social technology, Proceedings of INTCESS, 6th International Conference on Education and Social Sciences, 4-6 February, 687694.

Terziev, V. 2020, Provision of integrated employment and social assistance services in Bulgaria. Proceedings of International Scientific Conference FarEastCon 2018, 138, 24-39.

Terziev, V., Bencheva, N., Stoeva, T., Georgiev, M. 2020. Developing Social Entrepreneurship in the EU: A Cross-Country Analysis. SSRN Electronic Journal, 6, 37-44. DOI:10.2139/ssrn.3525681. 